DOI: https://doi.org/10.24297/jap.v16i1.8239

\title{
Effect of Terbium Additions on Microstructural, Thermal and Mechanical Properties of Eutectic Sn- 3.5Ag Pb- Free Solder for Low Cost Electronic Assembly
}

\author{
Rizk Mostafa Shalaby*, Fatma Elzahraa Ibrahim, Mostafa Kamal \\ Metal Physics Laboratory, Physics Department, Faculty of Science, Mansoura University, Mansoura, Egypt, \\ B.O.Box: 35516
}

*Corresponding author: rmibrahim99@gmail.com, rizk2002@mans.edu.eg

\begin{abstract}
This work methodically concentrated on the effect of a trace amount of rare earth element terbium, Tb (0.1, $0.2,0.3,0.4$ and $0.5 \mathrm{wt}$. \%) on the properties of eutectic Sn-3.5 wt. \%Ag were studied. The results indicated that addition of $\mathrm{Tb}$ rare earth can be refined the microstructure of the solder and intermetallic compound (IMC) Ag3Sn phase appeared in the solder matrix. Add a few quantity of rare earth Tb enhances the hardness and strength of eutectic Sn-Ag lead free solder joint. Also, results indicate that adding Tb to the eutectic Sn-3.5Ag remarkably enhances solderability, reliability, thermal and mechanical properties. It is also found that increasing in mechanical strength can depend on crystalline size refining in addition to some regular precipitates from IMC, Ag3Sn.
\end{abstract}

Keywords: eutectic Sn-Ag; lead free solder; Terbium additions; microstructures; mechanical properties; thermal properties.

\section{Introduction}

$\mathrm{Sn}-\mathrm{Pb}$ solders has been used before as interconnect materials extensively because of reliable, low cost ,the ease of processing, good solderability, good strength and forming of small intermetallic products . Nevertheless, the present industry going bound to the green products industry because of the health hazard and environmental regards standing on $\mathrm{Pb}$ solder alloys. At 2006, the EU has ordered the environmental standard called the ROHS demand that permitted the existence of substances in final products by less of 1,000 ppm (Ref 1). It is worth mentioning that the utilization of solders became an imperative for the interconnection, packing of practically all electronic devices and circuit present. Lead free solder alloy have been used widely as a part of electronic circuit for its excellent properties (Ref 2, 3). The type of lead free Sn-Ag solder is considered as a good alternative to $\mathrm{Sn}-\mathrm{Pb}$ solder (Ref 4). It gives a fine wettability, high strength in addition to better resistance to thermal fatigue and creep (Ref $5,6,7$ ). The development of new lead free solders at least with the same mechanical properties in addition to microstructures stability as eutectic $\mathrm{Pb}-\mathrm{Sn}$ solder is an urgent errand. In response to this, many candidate $\mathrm{Pb}$-free solder alloys as $\mathrm{Sn}-\mathrm{Ag}, \mathrm{Sn}-\mathrm{Zn}, \mathrm{Sn}-\mathrm{Sb}$, $\mathrm{Sn}-\mathrm{Bi}$, and $\mathrm{Sn}-\mathrm{Cu}$ been studied (Ref 8, 9, 10, 11). In general, lead free solder may be arranged into three temperature groups. These days, more consideration tends to research in to solder in the moderate temperature range like; Sn-Ag-Cu, Sn-Zn, Sn-Cu and Sn-Ag alloys (Ref 12, 13, 14). Sn-Ag alloys have been proposed as the good promising alternative for $\mathrm{Sn}$ - Pb solders (Ref 15 ). In the electronics industry, as the packing size decreased as well as service -environment required increase .It is necessary to search and provide new higher mechanical lead free solders.

To improve the effect of solder joints reliability, a group of ,Sn-Cu, Sn-Ag and Sn-Ag-Cu solders alloys doped with added substances was developed. Rare earth elements [REE] may significantly enhanced the properties of metal .Even all the rare earth element have fundamentally the same physical-chemical properties. REE are surface active element which has a vital part in metallurgy of materials like wettability and refinement microstructure of solder (Ref $16,17,18,19$ ) .It is common knowledge that microstructure change will influence 
the mechanical property, particularly in solder materials so RE doping can cause a change in mechanical property in solder alloys (Ref $20,21,22,23$ ). With refined microstructure from RE doping make the distance for dislocations to pile up making the doped solders have longer creep rupture time, better creep resistance and higher strength in tension with less elongation (Ref 24). Adding a little amount of rare earth element refines the microstructure in addition to IMC particles as well as makes the thickness of the interfacial IML thicker (Ref 25, 26). Terbium is member of the rare earth lanthanide group. It is a soft silver-gray metal, malleable, ductile. It is stable relatively in air compared to the earlier reactive lanthanides in the first half of the lanthanide series. It is found that literature survey revealed that lack studies on lead-free Sn-3.5Ag solder joints containing small trace of Tb rare earth element. So, the present work is devoted for investigating the effect of addition of trace amount of $\mathrm{Tb}$ rare earth element on microstructure, thermal, electrical and mechanical properties of Sn-3.5 wt. \% Ag lead free solder for trying to improve its microstructure physical properties.

\section{Experimental procedures}

\subsection{Materials}

Six solders alloys of compositions Sn 96.5-x Ag 3.5 Tb x ( $\mathrm{x}=0,0.1,0.2,0.3,0.4,0.5)$ were formed by using a single copper roller melt-spinning technique discussed elsewhere (Ref 27, 28). The metals used with required quantities of were weighed out and melted in a porcelain crucible. After the alloys melted the melt was completely agitated to have a homogenization effect. At $350^{\circ} \mathrm{C}$ melt temperature the casting was done in air. The copper wheel speed fixed at $2900 \mathrm{rpm}$; which agree with a linear speed of $30.4 \mathrm{~m} / \mathrm{s}$. By differential scanning calorimetry (DSC) which has a heating rate $10 \mathrm{~K} / \mathrm{min}$, the melting temperature of prepared alloys was obtained. The dynamic young's modulus and internal fiction of melt-spun alloys was calculated by a dynamic resonance method. The Vickers hardness measurements were examined by using a Vickers micro hardness tester. More than 15 indents to every value were made on every sample to determine any hardness variation caused by having more phases, with one phase soft, ductile and harder phase.

\subsection{Characterization}

The JEOL JSM-6510LV low vacuum scanning electron microscope (SEM) has a higher performance SEM for fast characterization and fine structures imaging (high resolution of $3.0 \mathrm{~nm}$ at $30 \mathrm{kV}$ ). It provides observation of specimens up to $150 \mathrm{~mm}$ in diameter. Identification of the as quenched melt- spun alloys was obtained by a Shimadzu x-ray diffractometer (Dx-30) (XRD). A Cu - K $\alpha$ radiation with wavelength, $\lambda=1.54056 \mathrm{~A}^{\circ}$ at $4.5 \mathrm{KV}$ and $35 \mathrm{~mA}$ with $\mathrm{N}$ Filter in the angular range $2 \theta$ ranging from $100^{\circ}$ to $800^{\circ}$ in continuous mode, which involves the strongest diffraction signals. When Bragg law is used to measure the interplanar spacing d', since $2 d^{\prime} \sin \theta=n \lambda$

\section{Results and discussion}

\subsection{Crystal Structures \& Lattice Parameters}

Lattice parameter data and crystal structure of stable phases observed in the Sn-3.5 Ag system are given in Table 1. Fig. 1 displays the patterns of $x$-ray diffraction for the melt-spun alloys. The pattern of the eutectic $\mathrm{Sn}$ 3.5Ag shows two phases, a tetragonal $\beta-\mathrm{Sn}$ matrix and orthorhombic Ag3Sn. For the alloys including terbium, the results indicate changes in main matrix microstructure (unit cell volume, lattice parameter and crystal size) and same phases appeared but with increasing the number of IMC phase. It is well known that the $\beta$-Sn tetragonal crystal has two axes a and $c$ and when the ratio of c/a rich to unity, a tetragonal cell becomes cubic. And therefore if the cubic cell is distorted along one axis, then it changes to tetragonal, its symmetry decreases, and forms more diffraction lines. The number of lines increases due to the new plane spacing introduction, resulted from non-uniform distortion. So the positions of all atoms found in the unit cell and specification of the lattice parameters is enough for characterize all essential aspects of a crystal structure. The 
lattice parameters $\mathrm{a}, \mathrm{c}$ and the axial variation ratio (c/a) are calculated for $\beta$-Sn matrix with the variation of $\mathrm{Tb}$ compositions and listed in the table 1 . The lattice particle size is estimated from $x$-ray pattern by using Scherer's equation where Dhkl $=0.891 \lambda / \beta h k l \cos \theta$. Lattice distortion $\langle\Sigma\rangle$ is calculated by $B=(1 /$ Deff $)+5<\Sigma 2$ $>1 / 2 \sin \theta / \lambda$ Deff where $B$ is full width high maximum (FWHM), Deff is the particle size, $\lambda$ is the wave length of

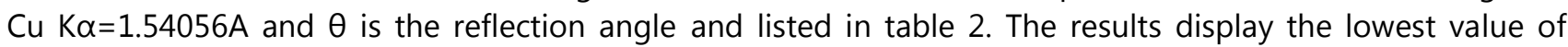
particle size was noticed for $\mathrm{Sn}-3.5 \mathrm{Ag}-0.5 \mathrm{~Tb}$ prepared alloy is $199 \mathrm{~nm}$ and display the maximum axial ratio c/a variation compared with other compositions.
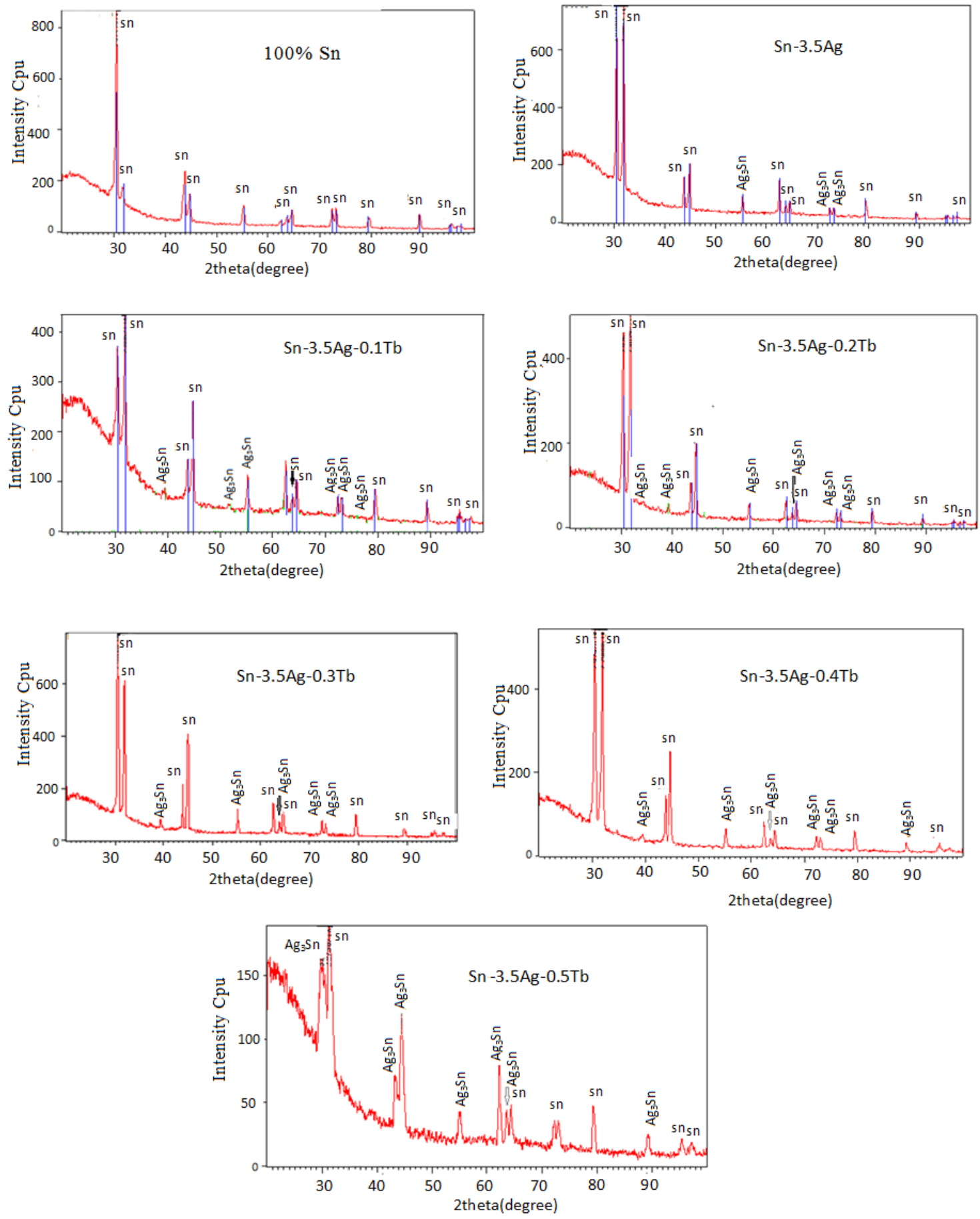

Fig. 1: The x-ray diffraction patterns of all Sn-3.5Ag-Tb lead

free solders 
Table 1: Lattice and cell parameters of Sn phase for Sn-3.5Ag-Tbx ( $x=0.0,0.1,0.3,0.4$ and 0.5 by wt. \%) alloys.

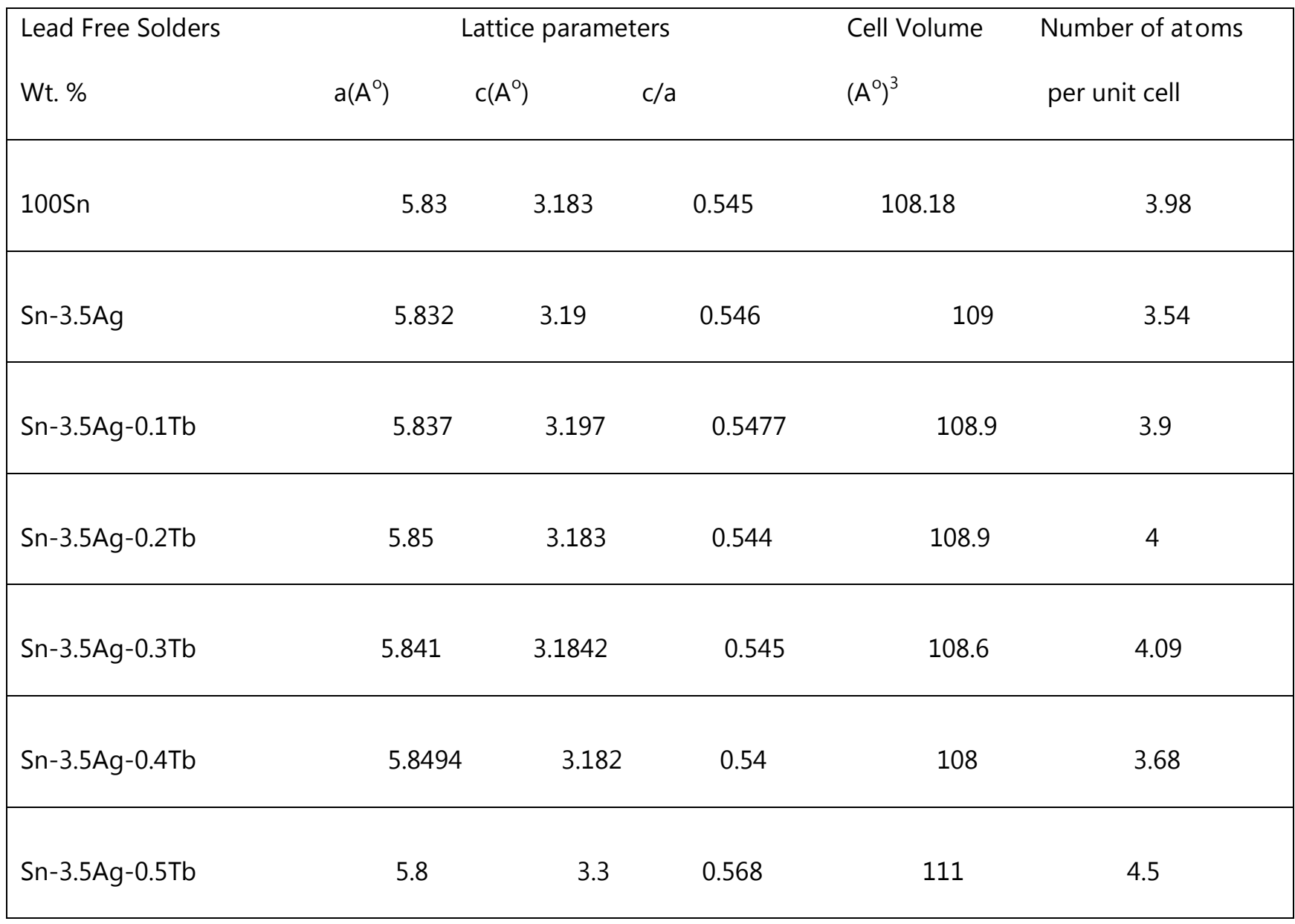


Table 2: Particle size and Lattice distortion for Sn-3.5Ag-Tbx ( $x=0.0,0.1,0.2,0.4$, and 0.5 by wt. \%) alloys.

\begin{tabular}{|c|c|c|c|c|c|}
\hline $\begin{array}{l}\text { Lead free solder } \\
\text { Wt.\% }\end{array}$ & $\begin{array}{l}\text { phase } \\
\text { designation }\end{array}$ & $\begin{array}{l}\text { Phase } \\
\text { no. }\end{array}$ & crystal system & $\begin{array}{l}\text { crystal } \\
\text { size }(\mathrm{nm})\end{array}$ & $\begin{array}{l}\text { Lattice } \\
\text { Distortion }\end{array}$ \\
\hline $100 S n$ & B-Sn & 13 & Tetragonal & 364.296 & $1.1 \mathrm{E}-03$ \\
\hline $\mathrm{Sn}-3.5 \mathrm{Ag}$ & $\begin{array}{l}\text { B-Sn } \\
\text { Ag3Sn }\end{array}$ & $\begin{array}{l}10 \\
3\end{array}$ & $\begin{array}{l}\text { Tetragonal } \\
\text { Orthorhombic }\end{array}$ & $\begin{array}{l}369 \\
317.45\end{array}$ & $\begin{array}{l}1.32 \mathrm{E}-03 \\
1.18 \mathrm{E}-03\end{array}$ \\
\hline Sn-3.5Ag-0.1Tb & $\begin{array}{l}\text { B-Sn } \\
\text { Ag3Sn }\end{array}$ & $\begin{array}{l}11 \\
6\end{array}$ & $\begin{array}{l}\text { Tetragonal } \\
\text { Orthorhombic }\end{array}$ & $\begin{array}{l}328 \\
507.465\end{array}$ & $\begin{array}{l}1.63 \mathrm{E}-03 \\
1.27 \mathrm{E}-03\end{array}$ \\
\hline Sn-3.5Ag-0.2Tb & $\begin{array}{l}\text { B-Sn } \\
\text { Ag3Sn }\end{array}$ & $\begin{array}{l}9 \\
5\end{array}$ & $\begin{array}{l}\text { Tetragonal } \\
\text { Orthorhombic }\end{array}$ & $\begin{array}{l}249.478 \\
295.28\end{array}$ & $\begin{array}{l}2.07 \mathrm{E}-03 \\
1.42 \mathrm{E}-03\end{array}$ \\
\hline Sn-3.5Ag-0.3Tb & $\begin{array}{l}\text { B-Sn } \\
\text { Ag3Sn }\end{array}$ & $\begin{array}{l}10 \\
5\end{array}$ & $\begin{array}{l}\text { Tetragonal } \\
\text { Orthorhombic }\end{array}$ & $\begin{array}{l}426 \\
326\end{array}$ & $\begin{array}{l}1.2 \mathrm{E}-03 \\
1.16 \mathrm{E}-03\end{array}$ \\
\hline Sn-3.5Ag-0.4Tb & $\begin{array}{l}\text { B-Sn } \\
A g 3 S n\end{array}$ & $\begin{array}{l}8 \\
6\end{array}$ & $\begin{array}{l}\text { Tetragonal } \\
\text { Orthorhombic }\end{array}$ & $\begin{array}{l}346 \\
326\end{array}$ & $\begin{array}{l}1.63 \mathrm{E}-03 \\
1.52 \mathrm{E}-03\end{array}$ \\
\hline Sn-3.5Ag-0.5Tb & $\begin{array}{l}\text { B-Sn } \\
\text { Ag3Sn }\end{array}$ & $\begin{array}{l}6 \\
7\end{array}$ & $\begin{array}{l}\text { Tetragonal } \\
\text { Orthorhombic }\end{array}$ & $\begin{array}{l}222 \\
199\end{array}$ & $\begin{array}{l}2.02 \mathrm{E}-03 \\
2.34 \mathrm{E}-03\end{array}$ \\
\hline
\end{tabular}

\subsection{Microstructures characterization change with the addition of rare earth, Tb.}

A scanning electron microscope (SEM) was used for examining the studied alloys microstructure. A typical microstructure of eutectic $\mathrm{Sn}-3.5 \mathrm{Ag}$ lead-free solder consists of a two mixture phases; a Sn-rich as dark contrast and eutectic structure which consists of $\beta-S n$ and $\mathrm{Ag}_{3} \mathrm{Sn}$ as bright contrast phase, as noted in Fig.2b. After added small amount from rare earth Tb to binary eutectic alloy, the ternary $\mathrm{Sn}-3.5 \mathrm{Ag}-\mathrm{Tb}$ microstructure composed of fine and uniformly particles of intermetallic compound $\mathrm{Ag}_{3} \mathrm{Sn}$ distributed in $\beta-\mathrm{Sn}$ matrix as noted in Fig.2d-g. The finer particles were identified as being $\mathrm{Ag}_{3} \mathrm{Sn} \mathrm{IMC} \mathrm{according} \mathrm{to} \mathrm{XRD} \mathrm{analysis.} \mathrm{The} \mathrm{volume}$ fraction of every phase is related to the compositions of alloys. The morphology of the IMC particles is superfine as indicated in structure. This effect could be attributed to the rapidly solidified and high cooling rate during the production of solders. It is found that rapid cooling during solidification processing by melt spun technique produces a finer microstructure as compared conventional methods Fig.2c-g. The 
microstructural features of a eutectic solder, like distribution, volume fraction, and spacing of every phase, give the physical and mechanical properties.
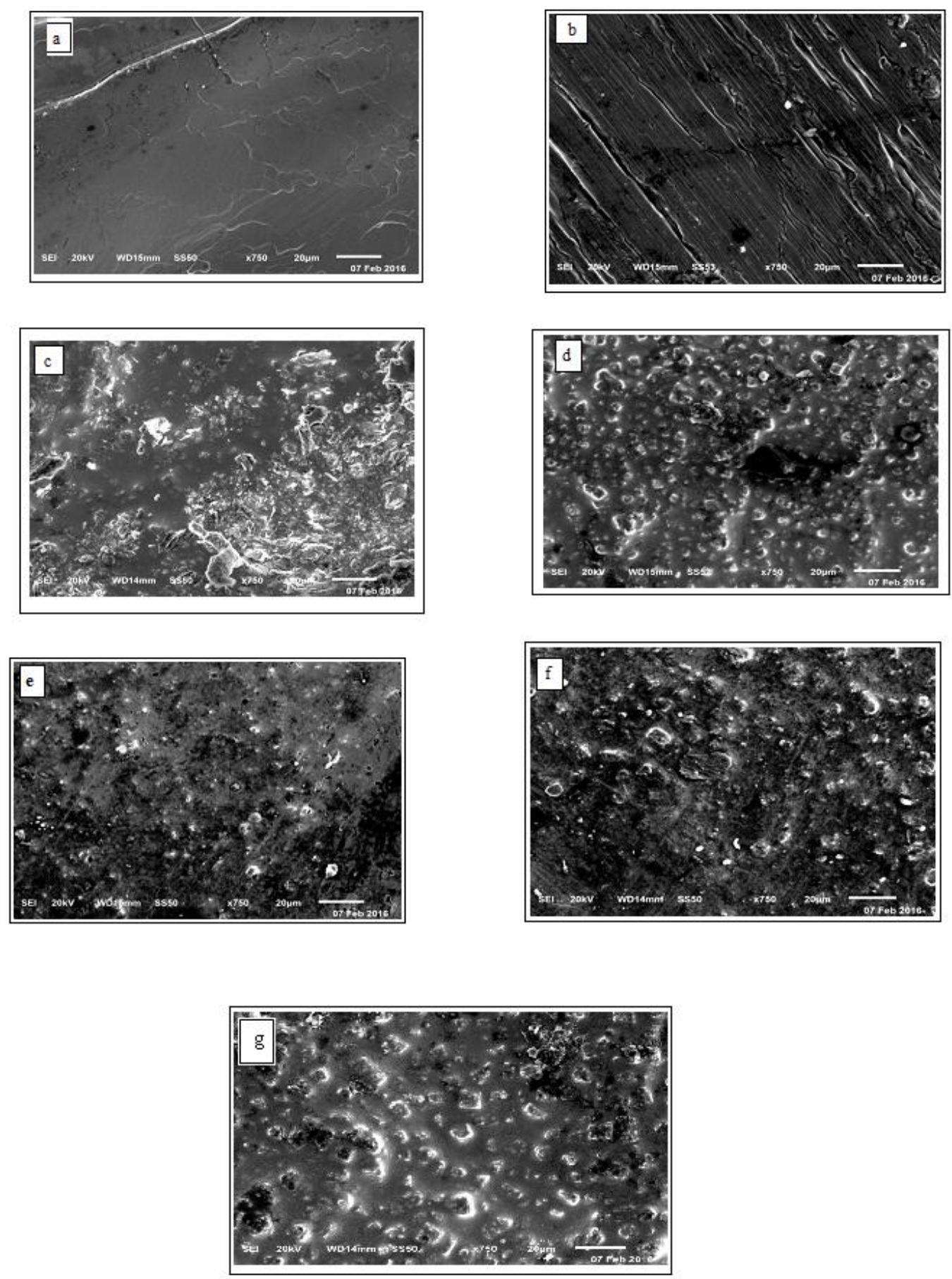

Fig. 2 SEM for (a)Sn, (b) $\mathrm{Sn}_{96.5}-\mathrm{Ag}_{3.5}$ (c) $\mathrm{Sn}_{964}-\mathrm{Ag}_{3.5}-\mathrm{Tb}_{0.1}$, (d) $\mathrm{Sn}_{96.3}-\mathrm{Ag}_{3.5}-\mathrm{Tb}_{0.2}$, (e) $\mathrm{Sn}_{962}-\mathrm{Ag}_{3.5}-\mathrm{Tb}_{0.3}$,

(f) $\mathrm{Sn}_{961}-\mathrm{Ag}_{35}-\mathrm{Tb}_{0.4}$ and (g) $\mathrm{Sn}_{96}-\mathrm{Ag}_{3.5}-\mathrm{Tb}_{0.5}$. 


\subsection{Thermal behavior}

By using the differential scanning calorimetry (DSC) the solder alloys melting temperatures is determined. The melting temperature $\left(T_{m}\right)$ is considered an important physical property of solder. The DSC curves for the eutectic and ternary solder alloys based on heating at scanning rate of $10^{\circ} \mathrm{C} / \mathrm{min}$ are shown in Fig.3. In the DSC curves, the melting point is typically calculated by first selecting the most steeping part of the low temperature side of well of the heat absorption, obtaining the slope, then extrapolating the slope line to the temperature at the zero differential heat flow axis. Tb substitution for Sn by weight in the Sn-3.5Ag eutectic reduced the melting temperature by few degrees. This decreasing is caused by the decrease of the crystalline size. This reducing is great because it is frequently not possible to reduce melting points of eutectic with ternary additions by $10{ }^{\circ} \mathrm{C}$ without making the phase equilibria complicating. The pasty is defined as the temperature difference between solidus and liquidus temperatures. In this temperature range the solder is a semi solid in addition to it gives different properties from the liquid or solid phases which during solidification lead to the solder left- off For the eutectic alloy Sn96.5-3.5Ag, the pasty range is equal to zero while the other alloys shows a positively increase up to $11.2^{\circ} \mathrm{C}$ as shown in table 3 . Using a solder with narrow pasty rang leads to avoid this problem. The results show, the lowest pasty range was achieved at $0.3 \mathrm{wt} \%$ addition. 

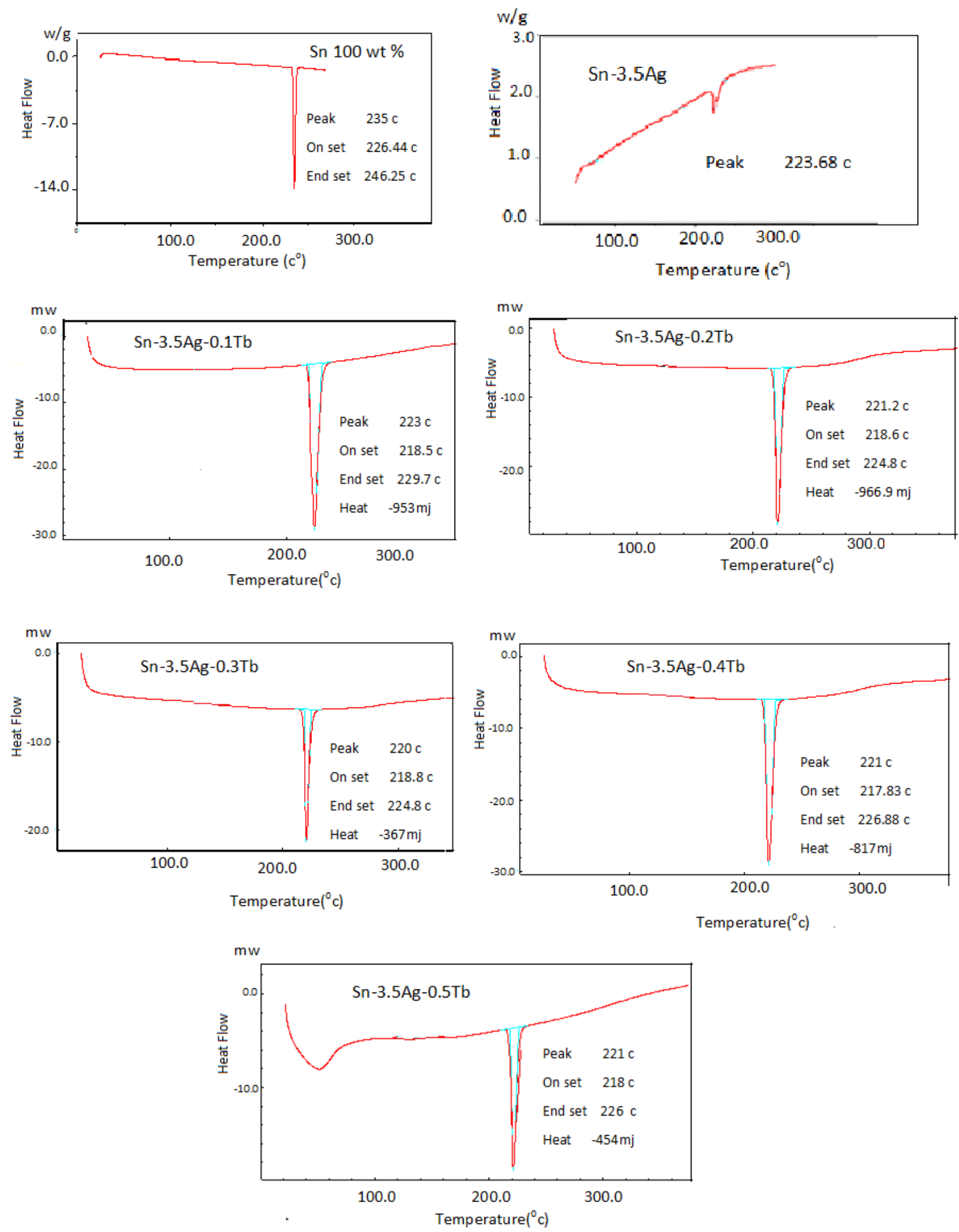

Fig.3 Differential scanning calorimetry (DSC) curves for lead free solder alloys 
Table 3: Thermal properties of Sn-3.5Ag-Tb lead free solder

\begin{tabular}{|lllll|}
\hline Lead free solder & $\begin{array}{l}\text { Solidus } \\
\text { temperature } \\
\mathbf{T}_{\mathbf{s}}(\cdot \mathbf{C})\end{array}$ & $\begin{array}{l}\text { Liquids } \\
\text { temperature } \\
\mathbf{T}_{\mathbf{I}}\left({ }^{\circ} \mathbf{C}\right)\end{array}$ & $\begin{array}{l}\text { Pasty } \\
\text { range }\left({ }^{\circ} \mathbf{C}\right)\end{array}$ & $\begin{array}{l}\text { melting point } \\
\mathbf{T}_{\mathbf{m}}\left({ }^{\circ} \mathbf{C}\right)\end{array}$ \\
\hline Sn & 226.44 & 242.25 & 15.81 & 235 \\
\hline Sn-3.5Ag & 222 & 228 & 6 & 221.68 \\
\hline Sn-3.5Ag- 0.1Tb & 218.50 & 229.70 & 11.20 & 223.70 \\
\hline Sn-3.5Ag- 0.2Tb & 218.62 & 226.57 & 07.95 & 221.22 \\
\hline Sn-3.5Ag- 0.3Tb & 218.80 & 224.80 & 06.00 & 220.20 \\
\hline Sn-3.5Ag- 0.4Tb & 217.83 & 226.88 & 09.05 & 221.06 \\
\hline Sn-3.5Ag- 0.5Tb & 218.40 & 226.10 & 07.70 & 221.30 \\
\hline
\end{tabular}

\subsection{Mechanical testing}

\subsubsection{Effect of Tb on Young's modulus}

The manufacture of modern electronic assemblies is depending on materials characterized by a broad range of thermal expansion coefficients. Normally heat generates within the electronic device operation. When these materials are matched together, during operation the physical restrictions produce internal thermal stresses and strains. The formation of intermetallic compound Ag3Sn may be responsible for the mechanical properties of solder joints. Increases the Tb contents above $0.1 \mathrm{wt}$. \% caused increase mechanical properties (Young's modulus). The material strength is related to the forces of atomic bonding that are reflected by the elastic modulus macroscopically. The influences of addition of Tb on elastic moduli were investigated in Table 4. The results show that the dynamic elastic modulus reached to the maximum value of $82 \mathrm{MPa}$ at $0.5 \mathrm{wt} . \% \mathrm{~Tb}$ approximately $100 \%$ so that the elastic modulus of Sn-3.5Ag-0.5Tb became two times as large as Sn-3.5Ag as shown in fig.4. This is may be because solid solution hardening effect and refining the micro structure of Ag3Sn IMC were identified by XRD that act as hard inclusions in main matrix Sn. But for 0.3Tb it be noticed that size of $\beta$-Sn particles were estimated from the XRD and found that the Ag3Sn particle size was increased from about $369 \mathrm{~nm}$ for un-doped alloy to about $426 \mathrm{~nm}$ for 0.3Tb doped alloy. The increased particles and grain increase the distance for dislocations to pile up, consequently the doped alloy has low elastic modulus. Also according to XRD it is found that 0, $4 \mathrm{~Tb}$ was added to melt tend to make formation of Ag3Sn intermetallic compound easier. Hence, increase the intermetallic compound phases, it led to increasing the elastic modulus of the Sn-Ag melt-spun solder alloys. 
Also, the results show that the internal friction has a sensitivity to the ratio of the added Tb component as one of the alloying elements to the binary Sn-3.5Ag as listed in Table 4. In Fig.5 the internal friction Q-1 changed with the content of $\mathrm{Tb}$ is shown by a reduction in transformable shear stress with biggest free volume. Values of shear modulus $(G)$ and bulk modulus (B) were determined using slandered equation $G=E / 2(1+U)$ and $\mathrm{B}=\mathrm{E} / 3(1-2 \mathrm{U})$. It is shown here that when $\mathrm{Pb}$-free solder alloys such that $\mathrm{Sn}-3.5 \mathrm{Ag}$ is doped with a small amount of RE elements, the mechanical properties of them are enhanced. The internal fraction and thermal diffusivity of alloys have been calculated by the resonance curves as shown in Fig. 6 and listed in the Table 4 .

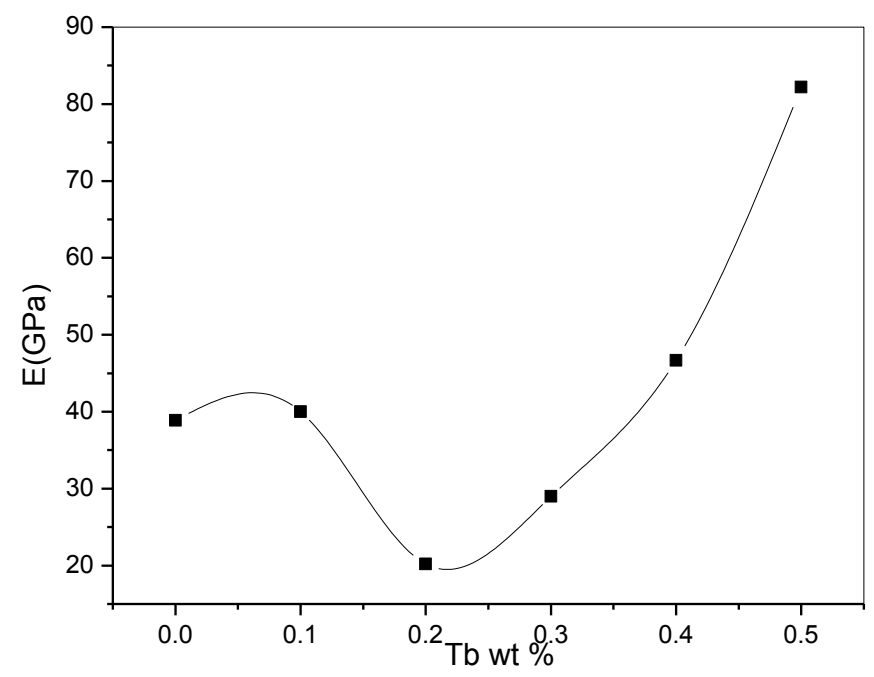

Fig 4: Young Modulus Variations with Tb addition for prepared lead free solder alloys

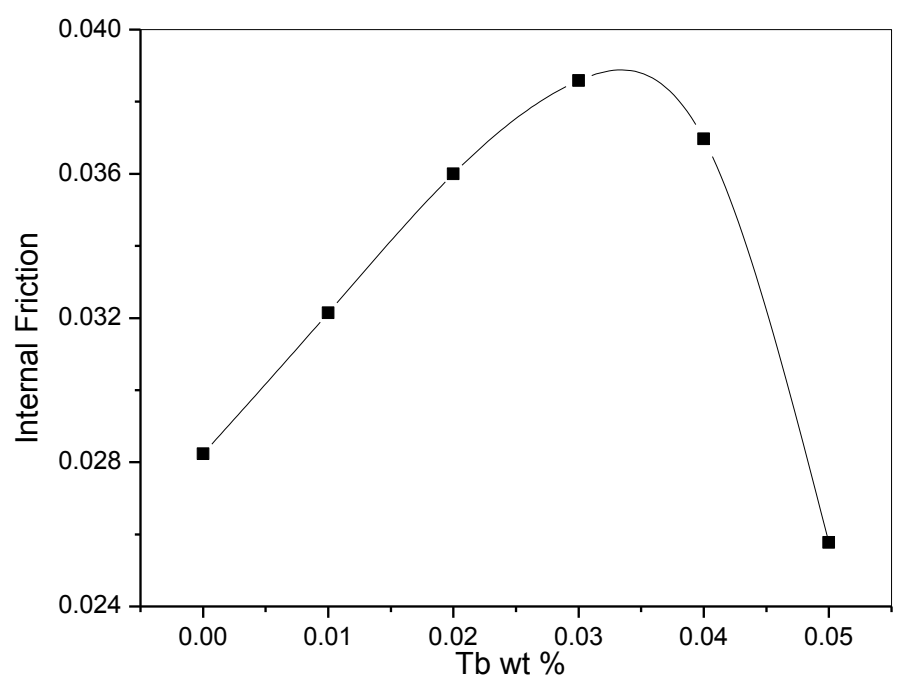

Fia 5: Internal Friction of Sn-3.5Aa Lead Free Solder Allovs 


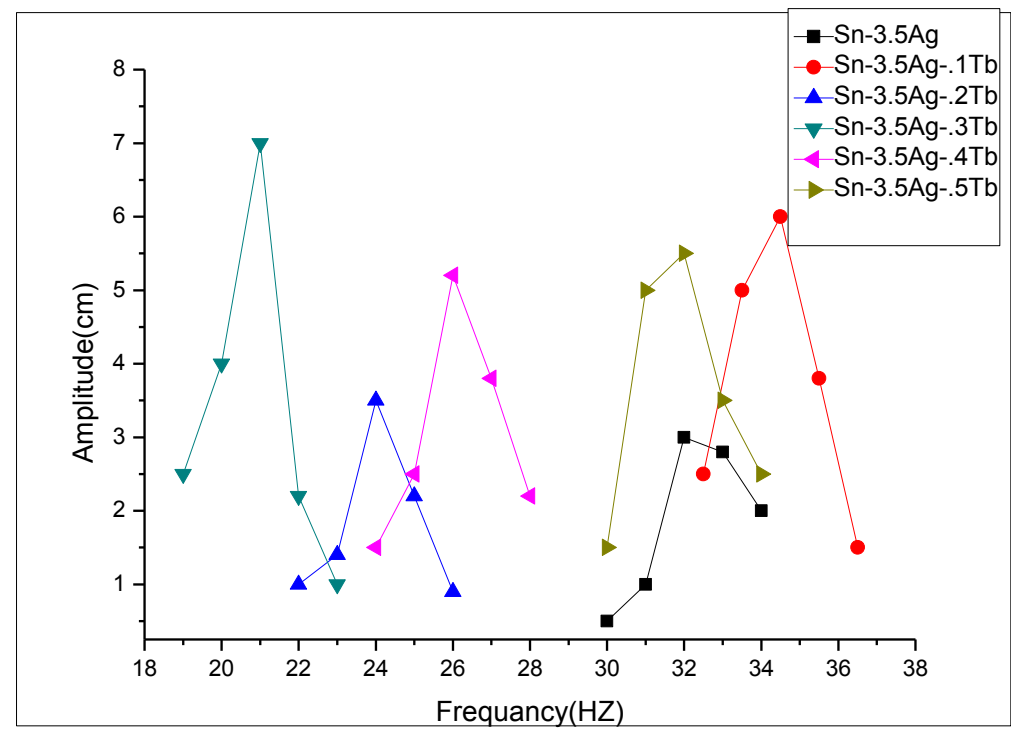

Fig 6: Resonance curves for lead free solder alloys

Table 4: Internal friction ( $Q-1)$ values and dynamic Young's modulus of prepared alloys

\begin{tabular}{|lcccc|}
\hline Lead free solder & $\mathrm{E}$ & $\mathrm{G}$ & $\mathrm{B}$ & $\mathrm{Q}-1$ \\
wt.\% & $\mathrm{GPa}$ & $\mathrm{GPa}$ & $\mathrm{GPa}$ & \\
\hline Sn & 37.4 & 13.8 & 43.6 & .0252 \\
\hline Sn-3.5Ag & 38.9 & 14 & 45 & 0.023 \\
\hline Sn-3.5Ag- 0.1Tb & 40 & 14 & 46.7 & 0.032 \\
\hline Sn-3.5Ag- 0.2Tb & 20.2 & 7.4 & 23.6 & 0.036 \\
\hline Sn-3.5Ag- 0.3Tb & 29 & 10.7 & 33.8 & 0.038 \\
\hline Sn-3.5Ag- 0.4Tb & 46.7 & 17 & 54.4 & 0.037 \\
\hline Sn-3.5Ag- 0.5Tb & 82.2 & 30.3 & 95.7 & 0.025 \\
\hline
\end{tabular}

\subsubsection{Effect of Tb on micro-hardness measurements}

The hardness measurement, especially, Vickers microhardness, gives a good indication of the mechanical properties of materials. The material hardness is often balanced with its resistance to attrition or wear and is a characteristic of practical interest since it calculated the material durability during use and the suitability particular applications of the material depend on it. The configuration of grains and the motion of dislocations and growth have an effect on the micro-hardness of a solder alloy. This process is more matched to the processing temperature, the microstructure, and the composition. By using an indentation hardness test the 
resistance to plastic indentation was calculated, by a standard load a small hard indenter is pressed into the surface and the indentation size resulted from it is obtained. Fig. 7 displays the influence of Tb content on Vickers hardness $\mathrm{Hv}$ at $10 \mathrm{gf}$ applied load and indentation time $5 \mathrm{~s}$. For $\mathrm{Sn}-3.5 \mathrm{Ag}, \mathrm{Hv}$ has the minimum value 149.6 MPa. After 0.2wt.\% level Tb addition the Hv increases up to $308.9 \mathrm{MPa}$ approximately $100 \%$ became two times eutectic Sn-3.5Ag composition as shown in Table 5. The micro-hardness value of Sn-3.5Ag solders increased with terbium content as a result of both dispersion strengthening and solid solution strengthening besides the increasing in intermetallic compound $\mathrm{Ag} 3 \mathrm{Sn}$ after rare earth addition as identified by XRD and refinement the grain size. Also, this conduct is illustrated in terms of the alloy structural properties. As therefor, the relatively high percent of hard Ag3Sn phase is almost present.

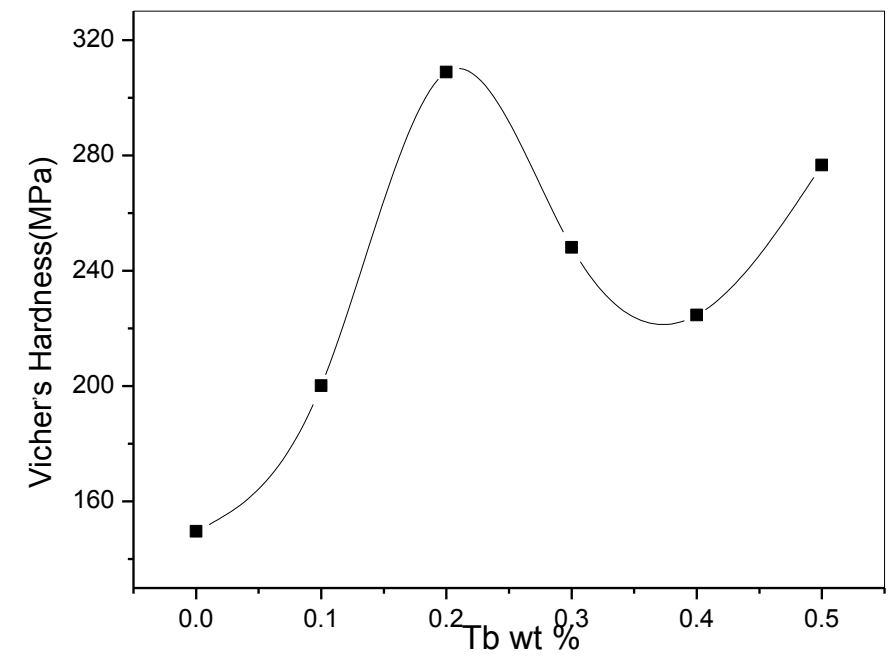

Fig 7: Vicher's Hardness of Sn-3.5Ag Lead Free Solder alloys

Table 5: Vickers hardness of Sn-3.5Ag-Tb lead free solder alloys

\begin{tabular}{|ll|}
\hline Lead free solder & Vickers micro-hardness \\
\hline Sn100 & $\mathrm{MPa}$ \\
\hline Sn-3.5Ag & 90.22 \\
\hline Sn-3.5Ag- 0.1Tb & 149.6 \\
\hline Sn-3.5Ag- 0.2Tb & 200.1 \\
\hline Sn-3.5Ag- 0.3Tb & 308.9 \\
\hline Sn-3.5Ag- 0.4Tb & 248.1 \\
\hline Sn-3.5Ag- 0.5Tb & 224.6 \\
\hline
\end{tabular}




\subsection{The wettability of $\mathrm{Pb}$-free solder doped with $\mathrm{RE}$, Tb.}

One of the famous ways to measure wettability of surface of material is contact angle Fig. 8 shows the contact angles for the prepared alloys formed at the solder substrate's flux triple point on Cu substrate in air .The results display that the wettability is enhanced by adding trace amount of rare earth $\mathrm{Tb}$ and the lowest contact angle was obtained when Tb content is 0.2 . The RE Tb can segregate on liquid solder surface because of it ${ }^{\mathrm{s}}$ reliability and surface activity. This segregation could lower the surface tension of the solder and makes the wettability of the solder much better. As much as rare earth elements are liable to be oxidizing during soldering forming slag .So with increasing of $\mathrm{Tb}$ addition led to lessen the solderability of solder.

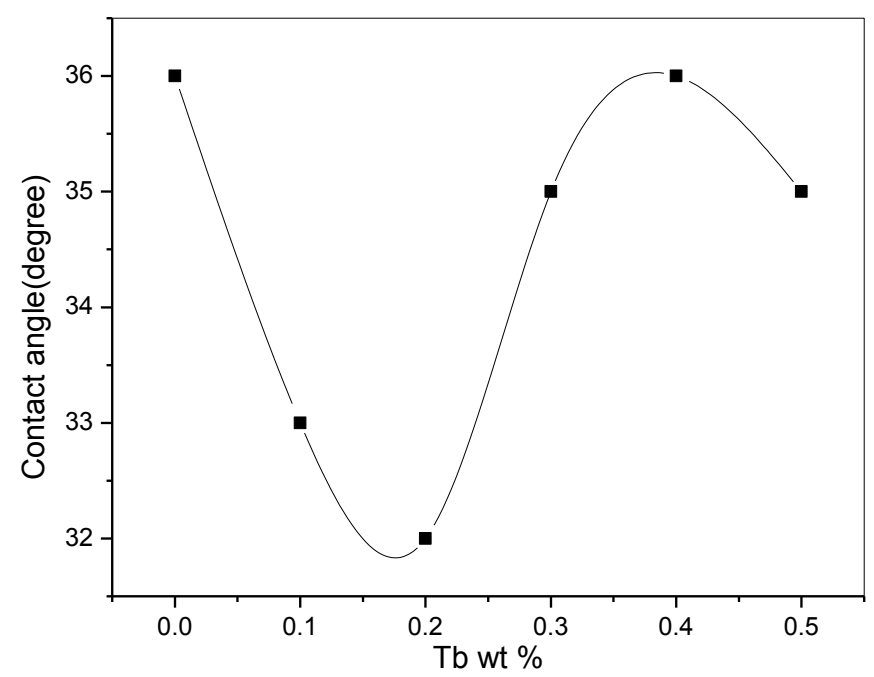

fig. 8: Contant angles of Sn-3.5Ag-Tb lead free solder alloys

\subsection{Electrical resistivity of $\mathrm{Pb}$-free solder doped with rare earth, Tb.}

In microelectronic devices assemblies the solder joint has a great effect on electrical interconnection. Therefore the solder interconnect resistivity in most microelectronic should be very thin that it does not have an effect on the circuit functionality. Fig.9 displays the electrical resistivity of prepared alloys at room temperature. The increasing in resistivity may is the result of the crystalline defects. The presence of crystalline defects is because of the formation of $\mathrm{Sn}$-Ag intermetallic compound that increased with $\mathrm{Tb}$ addition and works as scattering center for conduction electrons. Also, the small grain (crystallite) size of the alloy that obtained with $\mathrm{Tb}$ addition, the large number matrix, which may exist, can probably cause anomalous increase in the resistivity [29]. 


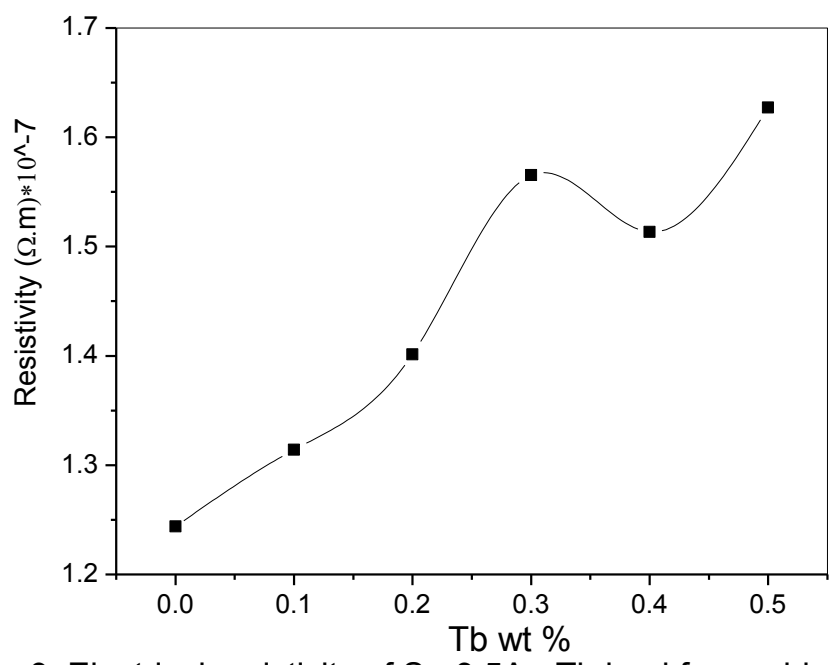

fig.9: Electrical resistivity of $\mathrm{Sn}-3.5 \mathrm{Ag}-\mathrm{Tb}$ lead free solder alloys

\section{Conclusions}

In general, adding trace amount of RE element plays an important role on the microstructure, mechanical, thermal and electrical of $\mathrm{Sn}-\mathrm{Ag}$ solder has investigated. The results show that, the micro-structure of $\mathrm{Sn}-3.5 \mathrm{Ag}$ solder become finer and uniform by adding Tb that may be due to the surface activity of REE. RE doping can also cause mechanical property change in solder alloys. With refined microstructure from RE doping, older show improved elastic modulus and Vickers hardness that was evident in 0.5Tb addition .while at 0.3Tb It be noticed that size of $\beta$-Sn particle size was increased Causing an increase in the distance for dislocations to pile up, consequently the doped alloy has low elastic modulus. Increasing the intermetallic compound phases led to improve the elastic modulus of the $\mathrm{Sn}-3.5 \mathrm{Ag}-0.4 \mathrm{~Tb}$ melt-spun solder alloys slightly. At the same time the rare earth addition has small effect on the melting temperature. Also, at different addition of REE, Tb, the electrical resistivity values have little increasing that may be as a result of forming of Ag3Sn IMC which acts as scattering centers for conduction electrons.

\section{References}

1. Ku, A., Oetinscitan, O., Saphores, J.-D., and Shapirod, A., Schoenunp, J.M.," Lead-free solders. issues of toxicity, availability and impacts of extraction, "Electronic Components and Technology Conference, 2003, p. 47 - 53(in English)

2. M.H.Braga, J. Vizdal ,A.Kroup, J.Ferreirad, D.Soares, and L.F.Malheiros, "The experimental study of the Bi-Sn, Bi-Zn and Bi-Sn-Zn system," Science Direct., 2007,31, p.468-478(in English)

3. A.A.EL-Daly,Y.swilim ,M.H.Makleb ,M.G Elshaarawy, and A.M.Abdraboh, "Thermal and mechanical of Sn-Zn-Bi lead-free solder alloys, "J. alloys and compounds., 2009,484, p.134-142,(in English)

4. ZHAI Wei, and WEI Bingo, "Thermodynamic properties and microstructural characteristics of binary Ag-Sn alloys,"Material .sci., 2013,58(8), p.938-944 (in English)

5. M.Kamal, and E.S. Goda, "Enhancement of solder properties of Sn-9Zn lead -free solder alloy,"cryst.res.Technol., ， 2006,41(12), p.1210-1213(in English)

6. R. M.Shalaby, "Indium, chromium and nickel - modified eutectic Sn- 0.7 wt.\% rapidly solidified from molten state," J.Materials Sci, Mater Electron, 2015,26(9), p.6625-6632(in English) 
7. R. M.Shalaby, "Effect of rapid solidification on microstructure, creep resistance and thermal properties of Sn-10 wt.\% Sb- 3 wt.\% X ( X= In, Ag, Bi and Zn) lead-free solder alloys", J. Advances in Physics,2015,9(1), p.2287-2298(in English)

8. R. M. Shalaby, and Mustafa Kamal, "Influence of In and Se addition on the mechanical properties of Sn-5Sb-2Cu bearing alloys,"International Journal of Physics and Research(IJPR).,2013,3,p.51-60(in English)

9. Mustafa Kamal, and R. M. Shalaby," Effect of reactive metal on creep resistance of Sn-50Bi lead free solder alloys," International Journal of Physics and Research(IJPR),2014,4(5), p.19-28(in English)

10. R.M.Shalaby, "Effect of silver and indium addition on mechanical properties and indentation creep behavior of rapidly solidified Bi-Sn based lead-free solder alloys," Materials Science and Engineering A., 2013,560, p.86-95(in English)

11. R.M.Shalaby, "Influence of indium addition on structure, mechanical, thermal and electrical properties of tin-antimony based metallic alloys quenched from melt, "Journal of Alloys and Compounds.,2009,25(2), p.334-339(in English)

12. R.M.Shalaby, "Effect of Silicon Addition on Mechanical and electrical properties of Sn-Zn based alloys rapidly quenched from melt, "Materials Science and Engineering A., 2012,550, p.112-117(in English)

13. R.M.Shalaby, "Effect of indium content and rapid solidification on microhardness and micro-creep of Sn-Zn eutectic lead free solder alloy," Crystal Research and Technology,2010,45(4),p.427-432(in English)

14. T.El-Ashram, and R.M.Shalaby, "Effect of rapid solidification and small additions of $\mathrm{Zn}$ and $\mathrm{Bi}$ on the structure and properties of Sn-Cu eutectic alloy, "Journal of Electronic Materials.,2005,34(2), p.212-215(in English)

15. R.M.Shalaby, "Effect of rapid solidification on mechanical properties of a lead free Sn-3.5Ag solder," Journal of Alloys and Compounds.,2010,505(1), p.113-117 (in English)

16. Prerna Mishra, S.N.Alam, and Rajinish Kumar, "Effect Of Rare Earth on Lead Free Solder Alloys", IJERA, ISSN.2284-9622, pp.80-86, (2014).

17. Boli,Yaowe Shi, Yon Gping lei, Zhidong Xia, and Bin Zong ,"Effect of Rare Earth Element Addition on the Microstructure of Sn-Ag-Cu Solder Joint ,"J. Electronic Materials.,2005,34(3), p.217-224 (in English)

18. Yaoeu Shi, Jun Tian, Hu Hao, Zhidong Xia, Youngping Lei, and Fu Guo ,"Effects of small amount addition of rare earth Er on microstructure and property of SnAgCu solder, "J,alloys and compounds.,2008, 453 ,p.180-184 (in English)

19. Jun Shen .Cuiping and $\mathrm{Wu}$. Shizeng $\mathrm{Li}$,"Effects of rare earth additions on the microstructural evolution and microhardness of Sn30Bio.5Cu and Sn35BilAg solder alloys,"J Mater Sci .Mater electron., 2012,23 ,p.156163(in English)

20. ZHAO Xiao-yan, ZHAO Mai-qun, CUI Xiao_qing, XU Tian-han, and TONG Ming-xin ,"Effect of cerium on microstructure and mechanical properties of $\mathrm{Sn}-\mathrm{Ag}-\mathrm{Cu}$ system lead-free solder alloys "Science Press., 2007,17,p. 805-810(in English)

21. Lili Gao, Songbai Xui, Liang Zhong Sheng, GuangZeng, and Feng Ji ,"Effects of trace rare earth Nd addition on microstructure and properties of SnAgCu solder," J Mater Sci. Mater Electron.,2010,21,p.643-648(in English) 
22. Liang Zhang, Song-bai Xue .Li-li Gao, Yan Chen, Sheng-lin Yu, Zhong Sheng, and Guang Zeng "Effect of trace amount addition of rare earth on properties and microstructure of Sn-Ag-Cu alloys" J mater Sci. Mater electronic.,2009,20, p.1193-1119(in English)

23. Lu Zhong, Zhou Jian, SUN Zhimei, and CHEN RongShi ,"Effect of rare earth elements on the structures and mechanical properties of magnesium alloys," Materials science.,2013, 58(7), p.816-820(in English)

24. ZHANG Liang, XUE Song-bai, GAO Li-li, ZENG Guang,CHEN Yan, YU Sheng-lin, and SHENG Zhong ,"Creep behavior of SnAgCu with rare Ce doping ",Science Direct.,2010,20, p.412-417(in English)

25. WenXue Chen, Songbai Xue, YuHua Hu, and Jianxin Wang," Effect of rare earth Ce on properties of Sn-9Zn lead- free solder", J Mater sci .Mater Electron, 2010, 21, p.719-725(in English)

26. Janka CHRIASTELOVA, Katarina POCISKOVA DIMOVA, Lydia RIZEKOVA TRNKOVA, Jan LOKAJ, Milan TURNA, and MILAN OZVOLD,"Intermetallic Compounds Formed Between Cu Substrates And Lead-Free Solders Containing Ce" ,Metal .,2010, 8,(in English)

27. M.Kamal, A.M.Shaban, M.El-Kady and R.M.Shalaby," Irradiation, mechanical and structure behavior of Aluminium-Zinc based alloys rapidly quenched from melt", Radiation Effects and Defects in Solids, OPA.,1996,138, p.307-318(in English)

28. M.Kamal, A.M.Shaban, M.El-Kady and R.M.Shalaby," Determination of structure-property of rapidly quenched aluminium-based bearing alloys before and after gamma irradiation", 2nd International Conference of Engineering Physics and Mathematics, Faculty of Engineering, Cairo University, Cairo.,1994,2, p.107-121(in English)

29. Robert M. Ras, Lawrence A. Shepard, John Weilff, Structure and properties of materials, Electronic properties, W.E.P. Ltd. 3rd Edn1992, ,4, p.333(in English) 